\title{
BMJ Open How defensive medicine is defined and understood in European medical literature: protocol for a systematic review
}

\author{
Nathalie Baungaard (D) , ${ }^{1}$ Pia Skovvang, ${ }^{1}$ Elisabeth Assing Hvidt (D) ,1,2 \\ Helle Gerbild, ${ }^{3,4}$ Merethe Kirstine Andersen, ${ }^{1}$ Jesper Lykkegaard ${ }^{1}$
}

To cite: Baungaard N, Skovvang $\mathrm{P}$, Assing Hvidt E, et al. How defensive medicine is defined and understood in European medical literature: protocol for a systematic review. BMJ Open 2020;10:e034300. doi:10.1136/ bmjopen-2019-034300

- Prepublication history and additional material for this paper are available online. To view these files, please visit the journal online (http://dx.doi. org/10.1136/bmjopen-2019034300).

Received 02 0ctober 2019 Revised 18 December 2019 Accepted 27 January 2020

Check for updates

(C) Author(s) (or their employer(s)) 2020. Re-use permitted under CC BY-NC. No commercial re-use. See rights and permissions. Published by BMJ.

${ }^{1}$ Department of Public Health, Research Unit of General Practice, Faculty of Health Sciences, University of Southern Denmark, Odense, Denmark ${ }^{2}$ Department for the Study of Culture, University of Southern Denmark, Odense, Denmark

${ }^{3}$ Center for Sexology Research, Department of Clinical Medicine, Aalborg Universitet, Aalborg, Denmark

${ }^{4}$ Health Sciences Research Centre University College, University College Lillebaelt, Campus Odense, Odense, Denmark

Correspondence to Nathalie Baungaard; nathaliebaungaard@gmail.com

\section{ABSTRACT}

Introduction The term defensive medicine, referring to actions motivated primarily by litigious concerns, originates from the USA and has been used in medical research literature since the late 1960s. Differences in medical legal systems between the US and most European countries with no tort legislation raise the question whether the US definition of defensive medicine holds true in Europe.

Aim To present the protocol of a systematic review investigating variations in definitions and understandings of the term 'defensive medicine' in European research articles.

Methods and analysis In concordance with the Preferred Reporting Items for Systematic Reviews and Meta-Analyses guidelines, a systematic review of all medical research literature that investigate defensive medicine will be performed by two independent reviewers. The databases PubMed, Embase and Cochrane will be systematically searched on the basis of predetermined criteria. Data from all included European studies will systematically be extracted including the studies' definitions and understandings of defensive medicine, especially the motives for doing medical actions that the study regards as 'defensive'.

Ethics and dissemination No ethics clearance is required as no primary data will be collected. The results of the systematic review will be published in a peerreviewed, international journal.

PROSPERO registration number This review has been submitted to International Prospective Register of Systematic Reviews (PROSPERO) and is awaiting registration.

\section{INTRODUCTION}

\section{Background}

Defensive medicine (DM) is a term that has been used in the medical research literature since the late 1960s. ${ }^{1}$ The term originates from the $\mathrm{US}^{2}$ and has since then taken on various connotations. ${ }^{3}$ The most commonly used definition describes DM as 'physicians' deviations from sound medical practice due to fear of liability claims and lawsuits' ${ }^{4-8} \mathrm{DM}$
Strengths and limitations of this study

- The present systematic review will be based on a systematic and thorough search of literature independently performed by two reviewers concordant with the Preferred Reporting Items for Systematic Reviews and Meta-Analyses guidelines, hereby increasing the generalisability and reliability of the findings.

- The scientific quality of each reviewed study will be assessed by use of standardised quality assessment tools and only the content of peer-reviewed original research papers will be included in the analysis.

- Only English language studies will be included in the systematic review.

can additionally be subdivided into two main forms of behaviour: (1) positive DM (also labelled active DM or assurance behaviour), which involves physicians ordering extra diagnostic tests, procedures or visits and (2) negative DM (also labelled passive DM or avoidance behaviour) which is the avoidance of high-risk patients or procedures. Both forms aim to reduce physicians' exposure to malpractice liability. ${ }^{4-7}$ The above definition of DM consists of two components: A medical action and an underlying motive for acting defensively.

DM has been associated with rising healthcare costs. ${ }^{7}$ Furthermore, it has been associated with overtreatment, overprescription and overdiagnosing of patients and decreased trust in the physician-patient relationship, leading patients to mistrust physicians' motivations and physicians to regard patients as potential plaintiffs. ${ }^{7-12}$ Moreover, physicians report patient disrespect for their professionalism, personal frustration and inequality in healthcare as possible consequences of DM. ${ }^{1314}$ 
In the USA, DM is reported to be frequent. ${ }^{15}$ The number of lawsuits for medical malpractice has risen significantly, ${ }^{9}$ and DM has been shown to be directly related to this growth. ${ }^{12}$ US physicians are forced to hold expensive malpractice insurances in order to cover the cost from malpractice suits. ${ }^{16}$ Hence, with inadequate legislation protecting physicians from tort, concerns about malpractice liability is likely to be the predominant reason to act defensively. ${ }^{7}$ Indeed, negative associations have been found between physicians' use of medical resources and risk of malpractice claims. ${ }^{17}$

In several European countries malpractice litigation is reported to happen less frequently than in the USA, for example in The Netherlands, ${ }^{218}$ Denmark,${ }^{13}$ Switzerland ${ }^{19}$ and the UK. ${ }^{20}$ In these countries, the medicolegal system does not hold physicians financially liable for malpractice or other treatment related adverse events. The patients are instead compensated by the government (known as a no-fault system).${ }^{21-23}$ Nevertheless, DM seems also to be prevalent in Europe, for example Denmark ${ }^{13}$ the UK, ${ }^{24}$ Italy, ${ }^{12}$ Belgium,${ }^{25}$ The Netherlands, ${ }^{2}$ Germany ${ }^{26}$ and Switzerland. ${ }^{20}$ Furthermore, a substantial part of research on DM seems to originate from Europe.

Variations in medicolegal systems between the US and most European countries raise the question whether the definition of DM, as actions motivated primarily by litigious concerns, holds true in European countries where physicians are not subjected to tort legislation ${ }^{20}$ and if other motives for performing defensive medical actions are documented in the European literature on DM. ${ }^{27}$

\section{Rationale}

Science needs definitions. To our knowledge no systematic review exists of how DM is defined and understood in the European scientific, medical literature. A systematic review of the term 'defensive medicine' in the European context will provide a more nuanced understanding of this complex and non-beneficial phenomenon, hereby supporting the quality of future research on the topic.

\section{Objectives}

The aim of this study is to present a protocol paper for a systematic review with the following objective: To analyse variations in the definitions and understandings of the term 'defensive medicine' in European research articles.

\section{METHODS}

\section{Patient and public involvement}

Patients or the public were not involved in the design, or conduct, or reporting, or dissemination of our research.

\section{Protocol}

This protocol for a systematic review is conducted in concordance with the PRISMA Protocol. ${ }^{28}$

\section{Eligibility criteria}

Publications will be included in the review based on the following criteria.
Inclusion criteria

1. One or both of the terms 'defensive medicine' and 'defensive practice' are stated in title or abstract.

2. The study is available in full text and written in English language.

3. DM is performed by physicians, including general practitioners, as well as physicians from medical, surgical and paraclinical specialities.

4. The study is an original research study (quantitative or qualitative primary research) or systematic review published in a peer-reviewed, medical journal.

5. DM is stated as part of the study's aim/objective in at least one of the following ways:

a. DM is included in the publication's aim/objective.

b. DM is implicitly a significant part of the aim/objective.

Further

6. The study's research data includes data from Europe.

\section{Information sources}

Eligible studies will be searched in three databases: PubMed, Embase and Cochrane from conception to February 3rd 2020.

\section{Search strategy}

The preparation of search strategy is based on the original American term 'defensive medicine'. In accordance with the database PubMed, the MeSH term 'defensive medicine' is combined with the entry terms 'defensive practice', 'defensive practices' and 'medicine, defensive'. On the basis of this, the following search strategy will be used: 'defensive medicine OR defensive practice OR defensive practices OR medicine, defensive'. All references in the papers fulfilling the inclusion criteria will be examined in order to identify potentially neglected studies. The literature search will be updated before the final analysis. See online supplementary appendix for detailed search strategy.

\section{Study records}

\section{Data management}

Publications found by the search strategy will be exported into the reference management software (EndNote) ${ }^{29}$ and the software Covidence ${ }^{30}$ where the systematic screening and data extraction will be performed, including the removing of duplicates. Number of citations for each study will be assessed with Web of Science ${ }^{31}$ in concordance with the PRISMA guidelines. ${ }^{28}$

\section{Selection process}

Two independent reviewers (NB and PS) will screen all potentially relevant studies in a two-phase screening process to ensure interrater reliability, compliance with the inclusion criteria and eligibility by use of Covidence. ${ }^{30}$ $\mathrm{NB}$ and PS will discuss and resolve any disagreements to reach consensus. If consensus is not achievable, a third reviewer (JL) will be involved in the discussion and finally decide whether the study in question is to be included or not. 


\section{Data collection process}

The primary authors (NB and PS) will extract data from the included studies, including publication details (author(s), name of journal, year of publication), study characteristics (design, country of origin, sample size, medical specialty investigated and number of citations), study objective, stated definitions of DM and understandings of DM.

\section{Quality assessment}

The two reviewers (NB and PS) will independently assess the quality of each study. The qualitative studies will be reviewed using the Critical Appraisal Skills Programme, ${ }^{32}$ recommended by the Centre for Clinical Guidelines (CFKR), ${ }^{33}$ to ensure a critical and standardised assessment of the quality and analysis of the study. The quantitative studies will be reviewed using a cross-sectional appraisal tool with questions adapted from Guyatt et al. JAMA 1993 and $1994 .^{34} 35$ The systematic reviews will be reviewed using Assessing the Methodological Quality of Systematic Reviews $^{36}$ recommended by the CFKR. ${ }^{33}$ Disagreements will be discussed until consensus is reached.

\section{Data items}

Data items are as stated above under 'methods'. The design of the review is based on the hypothesis that a definition of DM reflects the medicolegal system in which it is used. Therefore, we expect the definitions and understandings of DM stated in the European research literature to be different than those stated in the literature deriving from the USA.

\section{Data synthesis}

For each paper, the stated definition and understanding of DM will be extracted by the first author (NB). The definition of $\mathrm{DM}$ will be identified as: 'DM is...', ' $\mathrm{DM}$ is defined as...', 'DM refers to...', or 'DM is characterised by...'. If no definition of DM is stated, the way in which DM is introduced will be identified. A paper's understanding of DM is assessed from its use in the study and may differ from the stated definition. Quotes identifying how DM is understood will be extracted and analysed according to a thematic analysis approach aiming to categorise the different understandings. Based on the above definitions of DM, it is expected that the vast majority of papers will define DM as healthcare actions conducted by healthcare professionals during their work, but that the motives making the actions defensive may differ between papers showing a broader understanding of DM in some European studies than according to the US definition. Thus, for each paper, the motives regarded as defensive will be identified in the texts, tables, figures, as well as in the data collection methods. The identified categories of DM definitions and understandings will be scrutinised by the author group.

\section{Outcomes and prioritisation}

The review's main outcomes will be a categorisation of the identified definitions of DM in the European medical research literature focusing on the motives for medical acting that the studies regard as defensive and a graphical display of the historical trend in the annual number of published European original research papers regarding DM divided on the identified categories of DM definitions. The review will report if any differences in the definitions and understandings of DM between countries and between high-quality and low-quality papers exist.

\section{Risk of bias in individual studies}

Since the objective of this study differs from most systematic reviews by not taking interest in the results found by the reviewed studies, the quality assessment of the identified papers serves a different purpose. The assessment of the quality of the papers is used to show whether high quality papers use a different definition of DM than other papers (see the above-described quality assessment procedure).

Although there are multiple languages used in Europe, the review only includes English scientific literature. However, most high-ranking scientific journals reporting on DM is written in English and we specifically aim to support future research on DM. Furthermore, DM was originally conceptualised in English.

\section{CONCLUSION}

This systematic review will address the variations in the definitions and understandings of the term 'defensive medicine' in European research articles. This review seeks to provide a more nuanced understanding of the complex and non-beneficial phenomenon of DM, hereby supporting the quality of future research on the topic.

\section{Potential amendments}

We do not envisage any amendments to the present protocol. However, should an amendment be necessary, it will be notified, registered and reported.

Acknowledgements Research librarian, Lasse Østengaard, University of Southern Denmark for advice on the search strategy.

Contributors NB contributes to conceptualisation, protocol design, development of search strategy, study inclusion, data extraction, quality assessment, data analysis/ synthesis, drafting and writing of protocol and manuscript. PS contributes to conceptualisation, development of search strategy, study inclusion, data extraction, quality assessment, data analysis/synthesis, drafting and writing of manuscript. EAH contributes to conceptualisation, protocol design, writing of protocol and manuscript. HG contributes to conceptualisation, protocol design, writing of manuscript. MKA contributes to conceptualisation, protocol design, writing of manuscript. JL contributes to conceptualisation, protocol design, study inclusion, writing of protocol and manuscript.

Funding NB was supported by 'General practitioners' education and development fund' (Praktiserende Lægers Uddannelses og Udviklingsfond) with 27.810,00 DKK. EAH, HG, MKA and JL were financed through their institutions.

Disclaimer The funders had no role in developing the protocol.

Competing interests None declared.

Patient consent for publication Not required.

Provenance and peer review Not commissioned; externally peer reviewed.

Open access This is an open access article distributed in accordance with the Creative Commons Attribution Non Commercial (CC BY-NC 4.0) license, which 
permits others to distribute, remix, adapt, build upon this work non-commercially, and license their derivative works on different terms, provided the original work is properly cited, appropriate credit is given, any changes made indicated, and the use is non-commercial. See: http://creativecommons.org/licenses/by-nc/4.0/.

\section{ORCID iDs}

Nathalie Baungaard http://orcid.org/0000-0001-7311-2116

Elisabeth Assing Hvidt http://orcid.org/0000-0003-3762-8478

\section{REFERENCES}

1 Guthorn PJ. Toward a defensive stance in medical practice. J Med Soc N J 1968;65:548-9.

2 Veldhuis M. Defensive behavior of Dutch family physicians. widening the concept. Fam Med 1994;26:27-9.

3 Jones WA, Johnson JA, Williams SP. Controlling defensive medical practices and costs through state health policy reform. J Health Hum Serv Adm 1996;19:163-81.

4 Studdert DM, Mello MM, Sage WM, et al. Defensive medicine among high-risk specialist physicians in a volatile malpractice environment. JAMA 2005;293:2609-17.

5 Corrigan J, Wagner J, Wolfe L, et al. Medical malpractice reform and defensive medicine. Cancer Invest 1996;14:277-84.

6 OTA, Office of Technology Assessment. Defensive medicine and medical malpractice (online). (Publication No. OTA-H-602). Washington, DC, 1994. http://ota.fas.org/reports/9405.pdf

7 Panella M, Rinaldi C, Leigheb F, et al. Prevalence and costs of defensive medicine: a national survey of Italian physicians. $J$ Health Serv Res Policy 2017;22:211-7.

8 Hershey $\mathrm{N}$. The defensive practice of medicine. myth or reality. Milbank Mem Fund Q 1972;50:69-98.

9 Garcia-Retamero R, Galesic M. On defensive decision making: how doctors make decisions for their patients. Health Expect 2014;17:664-9.

10 Brateanu A, Schramm S, Hu B, et al. Quantifying the defensive medicine contribution to primary care costs. J Med Econ 2014;17:810-6.

11 Bourne T, Wynants L, Peters M, et al. The impact of complaints procedures on the welfare, health and clinical practise of 7926 doctors in the UK: a cross-sectional survey. BMJ Open 2015;5:e006687.

12 Catino M, Celotti S. The problem of defensive medicine: two Italian surveys. Stud Health Technol Inform 2009;148:206-21.

13 Assing Hvidt E, Lykkegaard J, Pedersen LB, et al. How is defensive medicine understood and experienced in a primary care setting? A qualitative focus group study among Danish general practitioners. BMJ Open 2017;7:e019851.

14 Assing Hvidt E, Bjørnskov Pedersen L, Lykkegaard J, et al. A colonized general practice? A critical habermasian analysis of how general practitioners experience defensive medicine in their everyday working life. Health (London) 2019:1363459319857461.

15 Hooe BS, Thakore RV, Issar N, et al. Do practice settings influence defensive medicine in orthopedic surgery? Am J Orthop 2014;43:E175-80.
16 Investopedia. Malpractice insurance (online). Available: https://www. investopedia.com/terms $/ \mathrm{m} / \mathrm{malpractice-insurance.asp} \mathrm{[Accessed} 6$ Aug 2018].

17 Jena AB, Schoemaker L, Bhattacharya J, et al. Physician spending and subsequent risk of malpractice claims: observational study. BMJ 2015;351:h5516.

18 Van Boven K, Dijksterhuis P, Lamberts H. Defensive testing in Dutch family practice. is the grass greener on the other side of the ocean? J Fam Pract 1997;44:468-72.

19 Rohacek M, Buatsi J, Szucs-Farkas Z, et al. Ordering CT pulmonary angiography to exclude pulmonary embolism: defense versus evidence in the emergency room. Intensive Care Med 2012;38:1345-51.

20 Steurer J, Held U, Schmidt M, et al. Legal concerns trigger prostatespecific antigen testing. J Eval Clin Pract 2009;15:390-2.

21 Antoci A, Fiori Maccioni A, Russu P. The ecology of defensive medicine and malpractice litigation. PLoS One 2016;11:e0150523.

22 Yan SC, Hulsbergen AFC, Muskens IS, et al. Defensive medicine among neurosurgeons in the Netherlands: a national survey. Acta Neurochir 2017;159:2341-50.

23 Kessler DP, Summerton N, Graham JR. Effects of the medical liability system in Australia, the UK, and the USA. Lancet 2006;368:240-6.

24 Summerton N. Trends in negative defensive medicine within general practice. Br J Gen Pract 2000;50:565-6.

25 Vandersteegen T, Marneffe W, Cleemput I, et al. The determinants of defensive medicine practices in Belgium. Health Econ Policy Law 2017;12:363-86.

26 Brilla R, Evers S, Deutschländer A, et al. Are neurology residents in the United States being taught defensive medicine? Clin Neurol Neurosurg 2006;108:374-7.

27 Ramella S, Mandoliti G, Trodella L, et al. The first survey on defensive medicine in radiation oncology. Radiol Med 2015;120:421-9.

28 Shamseer L, Moher D, Clarke M, et al. Preferred reporting items for systematic review and meta-analysis protocols (PRISMA-P) 2015: elaboration and explanation. BMJ 2015;349:g7647.

29 Web of Science Group. EndNoteX9 (online). Available: https:// endnote.com [Accessed Jul 2019].

30 Covidence(Online). Available: https://www.covidence.org/reviews [Accessed Jul 2019].

31 WebOfScience(Online). Available: www.webofknowledge.com/

32 CASP. Critical appraisal skills programme (2018). CASP (qualitative) checklist (online). Available: https://casp-uk.net/wp-content/uploads/ 2018/01/CASP-Qualitative-Checklist-2018.pdf [Accessed Jul 2019].

33 Center for kliniske retningslinjer. CASP tool (online). Available: http:// www.cfkr.dk/manualer-og-skabeloner/casp-instrumentet.aspx [Accessed Jul 2019].

34 Guyatt GH, Sackett DL, Cook DJ. Users' guides to the medical literature. II. How to use an article about therapy or prevention. A are the results of the study valid? evidence-based medicine Working group. JAMA 1993;270:2598-601.

35 Guyatt GH, Sackett DL, Cook DJ. Users' guides to the medical literature. II. How to use an article about therapy or prevention. B. what were the results and will they help me in caring for my patients? evidence-based medicine Working group. JAMA 1994;271:59-63.

36 Assessing the Methodological Quality of Systematic Reviews. AMSTAR Checklist(online). Available: http://amstar.ca/Amstar Checklist.php [Accessed Aug 2019]. 